\title{
Rapid distal small bowel transit associated with sympathetic denervation in type I diabetes mellitus
}

\author{
L Rosa-e-Silva, L E A Troncon, R B Oliveira, M C Foss, F J H N Braga, L Gallo Jr
}

\begin{abstract}
Background-The pattern of progression of a meal from the stomach to the caecum in diabetes mellitus is controversial and the differential roles of transit through the jejunum and the ileum have not been investigated in diabetes.
\end{abstract}

Aims-To determine gastric emptying and transit rates through proximal and distal regions of the small bowel in type $I$ diabetic patients.

Subjects-The study included six diabetic patients with evidence of autonomic neuropathy (DM-AN group), 11 diabetics without autonomic dysfunction (DM group), and 15 control volunteers.

Methods-Gastric emptying and small bowel transit of a liquid meal were evaluated scintigraphically in these subjects. Transit through regions of interest corresponding to the proximal and distal small intestine up to the caecum was determined and correlated with gastric emptying rates, cardiovascular measurements of autonomic function, and the occurrence of diarrhoea.

Results-Gastric emptying and transit through the proximal small bowel were similar in the three groups. The meal arrived to the caecum significantly earlier in DM-AN patients (median; range: 55 min; 22->180 min) than in the DM group $(100 \mathrm{~min}$; $44->180 \mathrm{~min}, p<0 \cdot 05)$ or in controls (120 min; 80->180 min, $p<0 \cdot 02)$. Accumulation of chyme in the distal small bowel was decreased in DM-AN patients, who showed values for peak activity $(30 \%$; $10-55 \%$ ) significantly lower than in the DM group (49\%; 25-77\%, $p=0.02)$ and controls $(50 \% ; 30-81 \%, p=0.02)$. In $D M$ patients $(n=17)$, the time of meal arrival to the caecum was significantly correlated with both orthostatic hypotension (coefficient of contingency, $\mathrm{C}=0.53, \mathrm{p}<0.01$ ) and diarrhoea $(C=0.47, p<0.05)$, but not with gastric emptying rates.

Conclusions-Patients with type I diabetes mellitus and sympathetic denervation have abnormally rapid transit of a liquid meal through the distal small bowel, which may play a part in diarrhoea production. (Gut 1996; 39: 748-756)

Keywords: diabetes mellitus, gastrointestinal transit, gastric emptying, small bowel transit, autonomic neuropathy, diabetic diarrhoea.

Abnormalities of gastrointestinal motility causing troublesome symptoms are well known complications of longstanding diabetes mellitus. ${ }^{12}$ These motor disorders seem to be more frequent in patients with evidence of autonomic neuropathy, ${ }^{2-5}$ which suggests a role for gut denervation in symptom production.

Involvement of the small bowel, in particular, has been thought to contribute to the pathophysiology in diabetic diarrhoea, ${ }^{12} 26$ and it has been proposed that abnormal small bowel motility and transit could cause diarrhoea through a number of mechanisms. ${ }^{1}$ Slow intestinal transit might be responsible for bacterial overgrowth ${ }^{7}$ whereas rapid transit would lead to diarrhoea due to intestinal hurry'. ${ }^{6}$ Nevertheless, studies concerning small intestinal transit in diabetic patients are not extensive and have produced conflicting results. Mouth to caecum transit time assessed by the hydrogen breath technique has been found to be prolonged ${ }^{2}$ or normal. $^{5910} \mathrm{On}$ the other hand, the passage of a barium meal through the gastrointestinal tract was reported to be accelerated in some patients with diabetic diarrhoea. ${ }^{6}$ Regardless of these discrepancies, the relation between gastric emptying and small bowel transit rates has not been extensively evaluated in diabetics.

In a previous study we found that patients with type I diabetes mellitus associated with autonomic neuropathy have abnormally rapid gastric emptying of liquids. ${ }^{4}$ We hypothesised that this abnormality could lead to accelerated transit through the entire length of the small bowel, thus contributing to diarrhoea production. This study therefore aimed to measure gastric emptying and transit through the small bowel after the ingestion of a liquid nutrient meal in type I diabetic patients with evidence of autonomic neuropathy. As there is evidence that the jejunum and the ileum display different transit patterns, ${ }^{11}$ we assessed the differential roles of proximal and distal small bowel in determining small intestinal transit.

The relations between gastrointestinal transit, signs of autonomic dysfunction affecting the cardiovascular system, and the occurrence of diarrhoea were also evaluated.

\section{Methods}

This study was carried out according to a protocol previously approved by the local ethics committee, with informed written consent obtained from each subject.

SUBJECTS

Patients

Seventeen unselected, insulin dependent type I diabetic men attending the diabetes mellitus 
outpatient clinic of the Hospital das Clínicas de Ribeirão Preto were included in this study. None of them had undergone previous operations on the gastrointestinal tract or a history of chronic alcoholism or pancreatic disease. None of the patients were taking any medication other than insulin.

Symptoms suggestive of autonomic neuropathy, ${ }^{12}$ such as postural hypotension, neurogenic bladder symptoms, sexual impotence, dysphagia, early satiety, nausea, vomiting, diarrhoea, constipation, and faecal incontinence were recorded using a specifically designed questionnaire. These symptoms were only attributed to diabetic neuropathy after excluding other conditions by the appropriate investigations. Six patients had symptoms suggestive of postural hypotension, two had evidence of neurogenic bladder, and four had sexual impotence. The only gastrointestinal symptom found in our patients was diarrhoea. Seven patients had occasional diarrhoea, with one to two days of elimination of liquid stools every 15-60 days, and one had chronic, continuous diarrhoea. However, this symptom was not the reason for seeking medical care except in the case with continuous diarrhoea.

Autonomic nerve function was assessed by three standardised cardiovascular reflex tests, which provided five measurements of vagal and sympathetic activities. On the basis of both the results of these tests and the questionnaire, diabetic patients were assigned to one of two groups. Six patients with at least one symptom suggestive of autonomic dysfunction plus abnormal results in at least two measurements in the cardiovascular nerve function tests represented a group of diabetics regarded as having autonomic neuropathy (DM-AN). The remaining 11 diabetics represented a group without autonomic neuropathy (DM). Table I gives the clinical data of the patients studied. No patient presented evidence of renal failure. All patients were regarded by their attending physicians as being fairly stable, as far as diabetes control was concerned, with no records of clinical or laboratory decompensation or increase in the usual insulin dose in the six month period preceding the study. On the morning of the day of the study, fasting plasma glucose concentrations (Table I) ranged from 3.8 to $14.0 \mathrm{mmol} / 1$ (median $=6.2$ $\mathrm{mmol} / \mathrm{l}$ ) for group $\mathrm{DM}$ and from 3.6 to 13.0 $\mathrm{mmol} / \mathrm{l}$ (median=8.3 $\mathrm{mmol} / \mathrm{l}$ ) for group DMAN. Urinary glucose excretion during the 24 hours preceding the gastrointestinal transit study ranged from 0 to $12 \mathrm{~g} / 24 \mathrm{~h}$ (median=4 $\mathrm{g} / 24 \mathrm{~h}$ ) for group DM and from 0 to $12 \mathrm{~g} / 24$ $\mathrm{h}($ median $=5 \cdot 7 \mathrm{~g} / 24 \mathrm{~h}$ ) for group DM-AN.

\section{Controls}

Fifteen non-diabetic, healthy male volunteers selected from the medical staff formed the control group. Median age in this group was 27 (range 18-45). No control patient was taking any medication or had clinical or laboratory evidence of diabetes mellitus or digestive diseases. Complaints of diarrhoea, constipation or changing bowel function were specifically denied by all control subjects. All controls were submitted to the cardiovascular autonomic nerve function tests. The gastrointestinal transit study was performed on 10 volunteers.

\section{STUDY DESIGN}

\section{Cardiovascular autonomic nerve function tests}

Autonomic nerve function was assessed by three standardised cardiovascular reflex tests: tilting test, detection of respiratory sinus arrhythmia (RSA), and the Valsalva manoeuver.

The head up tilting test with an inclination of $70^{\circ}$ was performed by means of a specially designed tilting table, which permitted acute passive changes in body position without muscular effort by the subject. ${ }^{13}$ Heart rate was monitored by continuous electrocardiographic (ECG) recording (Siemens-Elema Mingograf 34) and arterial blood pressure was measured in the right arm with a sphygmomanometer by the auscultation method.

RSA magnitude was determined in the supine position with the subjects breathing at a fixed respiratory rate of six cycles per minute. Instantaneous heart rate ( $R-R$ interval) was measured with a cardiotachometer (HewlettPackard, model 8812-A) and recorded on heat sensitive paper (Hewlett-Packard, model 7754-A). Beat to beat variation was reported as the mean value of the differences between maximum and minimum instantaneous heart rate during six respiratory cycles. ${ }^{14}$

The Valsalva manoeuver was also performed in the supine position by maintaining the intrathoracic pressure fairly constant at $40 \mathrm{~mm} \mathrm{Hg}$ for 15 seconds. Heart rate was continuously recorded on the ECG throughout the test. The ratio of the shortest $R-R$ interval during the

TABLE I Characteristics of diabetic patients with and without autonomic neuropathy $(A N)$ as defined by suggestive symptoms plus abnormal cardiovascular nerve function tests. Nephropathy was indicated by persistent microalbuminuria. Peripheral neuropathy (PN) was indicated by sensory and motor disturbances in a detailed physical examination

\begin{tabular}{|c|c|c|c|c|c|c|c|c|c|c|}
\hline \multirow[b]{2}{*}{$\begin{array}{l}\text { Diabetic } \\
\text { patients }\end{array}$} & \multirow[b]{2}{*}{$\begin{array}{l}\text { Age (y) } \\
m(r)\end{array}$} & \multirow[b]{2}{*}{$\begin{array}{l}\text { Duration of } \\
\text { diabetes } \\
\text { (y); } m(r)\end{array}$} & \multirow{2}{*}{$\begin{array}{l}\text { Blood } \\
\text { sugar } \\
(m m o l l) \\
m(r)\end{array}$} & \multirow[b]{2}{*}{$\begin{array}{l}\text { Nephropathy } \\
\text { (n) }\end{array}$} & \multirow[b]{2}{*}{$\begin{array}{l}\text { Retinopathy } \\
\text { (n) }\end{array}$} & \multirow[b]{2}{*}{$\begin{array}{l}P N \\
(n)\end{array}$} & \multicolumn{4}{|c|}{ Symptoms of $A N$} \\
\hline & & & & & & & $\begin{array}{l}P H \\
(n)\end{array}$ & $\begin{array}{l}N B \\
(n)\end{array}$ & $\begin{array}{l}S I \\
(n)\end{array}$ & $\begin{array}{l}D \\
(n)\end{array}$ \\
\hline $\begin{array}{l}\text { Without AN } \\
(\mathrm{n}=3)\end{array}$ & $\begin{array}{l}33 \\
(18-45)\end{array}$ & $\stackrel{9}{(2-31)}$ & $\begin{array}{l}6 \cdot 2 \\
(3 \cdot 8-14 \cdot 0)\end{array}$ & - & - & - & 1 & - & 1 & 3 \\
\hline $\begin{array}{l}\text { With AN } \\
(n=6)\end{array}$ & $\begin{array}{l}37 \cdot 5 \\
(27-40)\end{array}$ & $\begin{array}{l}12 \\
(11-13)\end{array}$ & $\begin{array}{l}8 \cdot 3 \\
(3 \cdot 6-13 \cdot 0)\end{array}$ & 4 & 4 & 4 & 5 & 2 & 3 & 5 \\
\hline
\end{tabular}

m=median; $r=$ range; $n=$ number of patients. $\mathrm{PH}=$ postural hypotension; $\mathrm{NB}=$ neurogenic bladder; $\mathrm{SI}=$ sexual impotence; $\mathrm{D}=$ diarrhoea. 
manoeuver to the longest $R-R$ interval 30 seconds after this manoeuver (Valsalva ratio) was calculated. ${ }^{13} 15$

These three cardiovascular tests yield five variables for the assessment of autonomic control: (1) heart rate variation during the first 10 seconds after tilting, for assessing vagal activity on sinus node ${ }^{15} ;(2)$ heart rate variation from the first to the fifth minute after tilting, for assessing sympathetic mechanism of heart rate increase ${ }^{15}$; (3) arterial pressure response to standing in the tilting test, for assessing peripheral sympathetic function ${ }^{15}$; (4) beat to beat variation in the RSA test, as an index of vagal activity, ${ }^{14}$ and (5) Valsalva ratio, for assessing sympathetic and vagal control mechanisms. ${ }^{1315} 16$ With the exception of blood pressure levels after tilting, results for diabetics were regarded as abnormal when an observed value was out of the range obtained for the control group. For arterial blood pressure, a fall in systolic levels of $30 \mathrm{~mm} \mathrm{Hg}$ or more or a fall in diastolic values of $10 \mathrm{~mm} \mathrm{Hg}$ or more, or both, were regarded as abnormal. ${ }^{16}$

Gastric emptying and gastrointestinal transit

Gastric emptying and gastrointestinal transit were determined at $100 \mathrm{pm}$, six hours after a light breakfast, which was preceded by the usual morning insulin dose. No food intake was permitted during this period.

A liquid test meal was prepared by mixing $10 \mathrm{~g}$ of wheat flour, two eggs, $15 \mathrm{~g}$ of dextrose, $40 \mathrm{~g}$ of sucrose, $10 \mathrm{~g}$ of chocolate, $15 \mathrm{~g}$ of casein, $250 \mathrm{ml}$ of water, and $18 \mathrm{~g}$ of lactulose (Epalfen, Zambon Farmaceuti, in Spa, Vicenza, Italy) in a food processor. This meal (800 mOsm) contained $437 \mathrm{Kcal}, 64 \mathrm{~g}$ of carbohydrate, $20 \mathrm{~g}$ of protein and $11 \mathrm{~g}$ of fat and was labelled with $18 \mathrm{MBq}$ of ${ }^{99 \mathrm{~m}}$ Technetium-sulphur colloid (Sulfursyd, Sydma Medical Equipments and Reagents, Ribeirão Preto, SP, Brazil) immediately before ingestion.

After ingestion of the liquid test meal was completed, the subject was placed upright in front of the hexagonal hole, low energy, high sensitivity collimator of a gammacamera (Orbiter Stand, Siemens Gammasonics, USA) coupled to a computer (Microdelta System, Siemens Gammasonics, USA). External markers (plastic needle cover containing cotton soaked in ${ }^{99 m}$ Technetium-sulphur colloid) were fixed to the skin, one on the right hypochondrium and the other on the right lower quadrant, $2 \mathrm{~cm}$ medially to the anterior superior iliac spine. The first marker allowed correction for body movements, whereas the second established the anatomical reference to the caecum. ${ }^{17}$ Serial images of the distribution of the ingested radioactivity over the anterior and posterior views of the abdomen were obtained every five minutes for the first 30 minutes and every 10 minutes for 180 minutes thereafter. Time zero was defined as the time of meal completion. Concomitantly, end expiratory breath air samples were collected immediately before and every 10 minutes after ingestion of the test meal for 180 minutes. ${ }^{18}$ Hydrogen $\left(\mathrm{H}_{2}\right)$ excretion was measured in each breath sample by means of a Microlyser gas chromatograph (Model 12, Quintron, Milwaukee, Wisconsin, USA).

DATA ANALYSIS

\section{Gastric emptying}

Regions of interest (ROIs) for the anterior and the posterior views of the stomach were defined on each scintigram. Decay corrected counts for both anterior and posterior gastric ROIs were geometrically averaged to correct for the posterior-anterior movement of the marker within the stomach. ${ }^{19} \mathrm{~A}$ time activity curve for the stomach was derived from these corrected data. Three parameters were determined by analysis of this curve. The percentages of initial activity remaining in the gastric area 15 minutes and 120 minutes after the meal were taken as indicating early and late gastric emptying (GE), respectively. The $t_{1 / 2}$ was defined as the period of time necessary for the activity in the gastric area to fall $50 \%$ from the initial levels.

\section{Gastrointestinal transit}

ROIs for the anterior view of the proximal and distal segments of the small bowel and the caecum were defined on each image according to procedures recommended by others, ${ }^{1120}$ as previously described. ${ }^{18}$ Initially, the progression of the radiolabelled meal was visually assessed by replaying the successive frames on the video monitor. Immediately after meal ingestion, the typical image of the stomach was seen in the first frames. Thereafter, activity leaving the stomach was seen on the left and immediately below the gastric area. As gastric emptying proceeded, activity was detected only briefly in this region, which remained nearly empty throughout the study. From this region, the radioactivity moved to the right and downward to the pelvic area, where it seemed to accumulate, forming a nearly round image before starting to ascend towards the caecum (Fig 1). Activity in each of these ROIs was expressed as the percentage of total abdominal activity so as

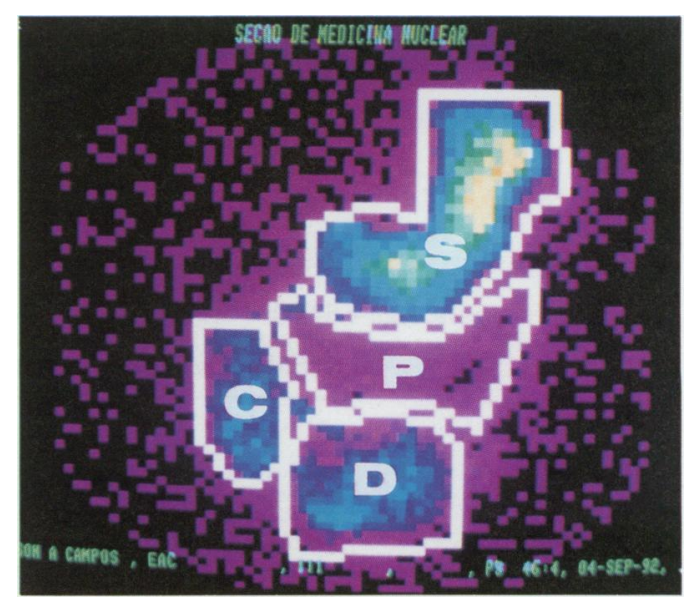

Figure 1: Scintigraphic image of the anterior abdomen after ingestion of a liquid meal tagged with ${ }^{99 m} T c$ illustrating the $R O I s$ defined for the stomach $(S)$, proximal $(P)$ and distal (D) small bowel, and the caecum (C). 
TABLE II Results of the cardiovascular tests in the control group and diabetic patients without (DM) and with autonomic neuropathy (DM-AN). Patients in the second group had at least one suggestive symptom plus abnormalities in at least two cardiovascular measurements

\begin{tabular}{|c|c|c|c|c|c|}
\hline Groups & $\begin{array}{l}H R d_{10} \\
m(r)\end{array}$ & $\begin{array}{l}H R d_{1-5} \\
m(r)\end{array}$ & $\begin{array}{l}\text { Postural } \\
\text { hypotension }\end{array}$ & $\begin{array}{l}R S A \\
m(r)\end{array}$ & $\begin{array}{l}V R \\
m(r)\end{array}$ \\
\hline $\begin{array}{l}\text { Control } \\
\text { DM } \\
\text { DM-AN }\end{array}$ & $\begin{array}{l}18 \cdot 0(8 \cdot 0-27 \cdot 0) \\
16 \cdot 0(9 \cdot 0-25 \cdot 0)\end{array}$ & $\begin{array}{l}16 \cdot 0(7 \cdot 0-26 \cdot 0) \\
13 \cdot 0(7 \cdot 2-23 \cdot 0)\end{array}$ & $\begin{array}{l}(-) \\
(-)\end{array}$ & $\begin{array}{l}18 \cdot 0(6 \cdot 0-37 \cdot 0) \\
17 \cdot 5(7 \cdot 0-29 \cdot 0)\end{array}$ & $\begin{array}{l}1.9(1.3-2.5) \\
1.8(1.4-2.0)\end{array}$ \\
\hline $\begin{array}{l}\text { (patient number) } \\
1 \\
2 \\
3 \\
4 \\
5 \\
6\end{array}$ & $\begin{array}{r}3 \cdot 2 \\
8 \cdot 9 \\
11 \cdot 0 \\
0 \cdot 0 \\
6 \cdot 0 \\
6 \cdot 0\end{array}$ & $\begin{array}{l}\text { Individual } \\
13.4 \\
15.5 \\
17 \cdot 2 \\
10.0 \\
21.6 \\
6.0\end{array}$ & $\begin{array}{l}\text { data } \\
(+) \\
(+) \\
(+) \\
(+) \\
(+) \\
(+)\end{array}$ & $\begin{array}{r}26 \cdot 8 \\
4 \cdot 3 \\
4 \cdot 0 \\
2 \cdot 1 \\
6 \cdot 3 \\
2 \cdot 0\end{array}$ & $\begin{array}{l}1 \cdot 6 \\
1 \cdot 2 \\
1 \cdot 4 \\
1.0 \\
1.9 \\
1 \cdot 1\end{array}$ \\
\hline
\end{tabular}

$H R d_{10}=$ heart rate variation during the first 10 seconds in the tilting test. $H R d_{1-5}=$ heart rate variation from the first to the fifth minute in the tilting test. Postural hypotension was defined as a fall of at least $30 \mathrm{~mm} \mathrm{Hg}$ in systolic levels or $10 \mathrm{~mm} \mathrm{Hg}$ in diastolic levels in the tiling test, or both. RSA=beat to beat variation in the respiratory sinus arrhythmia test. VR=valsalva ratio. $\mathrm{m}=$ median; $\mathrm{r}=$ range. $(-)=$ absent; $(+)=$ present.

to avoid further corrections. Counts from these ROIs were used to draw time activity curves for each intestinal segment. Analysis of these curves provided data for assessing both gastric emptying and the progression of the front of the meal throughout the small bowel up to the caecum. The time of meal arrival to the caecum $\left(t_{C}\right)$ was defined as the time required for the first appearance in the corresponding ROI of at least $10 \%$ of total abdominal activity. The $t_{C}$ values determined according to this definition were found to be highly correlated with orocaecal transit time, as determined by the $\mathrm{H}_{2}$ breath test. By analogy, the time of meal arrival to the proximal and distal small bowel was also defined as the time required for the first appearance of at least $10 \%$ of total abdominal activity in the corresponding ROIs. The transit of the bulk of the meal in the proximal and distal small bowel was assessed by computing the values for the activity remaining in each of these ROIs in each frame. Particularly, accumulation of the bulk of the meal in the distal small bowel was estimated by recording the peak activity for the corresponding ROI, which was defined as the highest count observed in this ROI at any time during the study.

\section{Orocaecal transit time (OCTT)}

This was defined as the time between meal intake and the first rise in $\mathrm{H}_{2}$ concentration of at least $5 \mathrm{ppm}$ above fasting values in at least three consecutive samples. ${ }^{18}$

STATISTICAL ANALYSIS

Non-parametric tests were used to analyse the results. ${ }^{21}$ The significance of the differences

TABLE II Gastric emptying (GE) of a liquid meal in controls and diabetic patients without (DM) and with (DM-AN) evidence of autonomic neuropathy. Early and late $G E$ correspond to the percentages of initial activity in the gastric area 15 minutes and 120 minutes after meal ingestion, respectively. $T_{1 / 2}$ is the time necessary for the activity in the gastric area to fall $50 \%$ from the initial levels. Data are reported as median and (range)

\begin{tabular}{llll}
\hline Subjects & Early GE (\%) & Late GE (\%) & $t_{1 / 2}(\mathrm{~min})$ \\
\hline Controls & $79 \cdot 8 \%$ & $21 \cdot 8 \%$ & $58 \cdot 5 \mathrm{~min}$ \\
$(\mathrm{n}=10)$ & $(51 \cdot 3-84 \cdot 4)$ & $(14 \cdot 6-30 \cdot 6)$ & $(16 \cdot 0-83 \cdot 0)$ \\
DM & $68 \cdot 2 \%$ & $11 \cdot 0 \%$ & $40 \cdot 0 \mathrm{~min}$ \\
$(\mathrm{n}=11)$ & $(39 \cdot 8-89 \cdot 5)$ & $(5 \cdot 2-39 \cdot 3)$ & $(5 \cdot 0-95 \cdot 0)$ \\
$\mathrm{DM}-\mathrm{AN}$ & $67 \cdot 6 \%$ & $12 \cdot 6 \%$ & $49 \cdot 5 \%$ \\
$(\mathrm{n}=6)$ & $(53 \cdot 4-81 \cdot 8)$ & $(5 \cdot 3-60 \cdot 5)$ & $(16 \cdot 0->180 \cdot 0)$ \\
\hline
\end{tabular}

$\mathrm{n}=$ number of subjects. between the three groups of subjects concerning each of the gastric emptying and gastrointestinal transit parameters was assessed by the Kruskal-Wallis test. Subsequent comparisons between pairs of groups were performed by the Mann-Whitney U test.

Correlations between gastric emptying and gastrointestinal transit data and between the results of cardiovascular tests and gastrointestinal transit data were assessed by the Spearman correlation coefficient $(r)$. The contingence coefficient (C) was used to analyse the correlations involving categorical data such as presence or absence of evidence of autonomic neuropathy, diarrhoea, and postural hypotension. For this correlation analysis, the data obtained for the two groups of diabetes were pooled.

Differences were taken as statistically significant for $p$ values of less than 0.05 .

\section{Results}

\section{CARDIOVASCULAR AUTONOMIC FUNCTION}

Three patients in the DM-AN group had abnormalities in three to five measurements of cardiovascular autonomic function. The remaining three patients in this group had abnormal results in only two measurements (Table II). Orthostatic hypotension, in particular, was detected in all patients in this group. On the contrary, none of the patients allocated to the DM group had abnormal results for any of the five cardiovascular measurements performed.

\section{GASTRIC EMPTYING}

Table III shows the results concerning the various parameters. Values for the activity remaining in the stomach in both groups of diabetics tended to be lower than those obtained in controls, but no statistically significant differences were observed regarding any of the parameters.

\section{GASTROINTESTINAL TRANSIT}

Analysis of the sequential images obtained for each subject revealed distinct patterns of gastrointestinal transit (Fig 2). In all controls and in nine DM patients, the stomach emptied evenly and the front of the meal travelled 

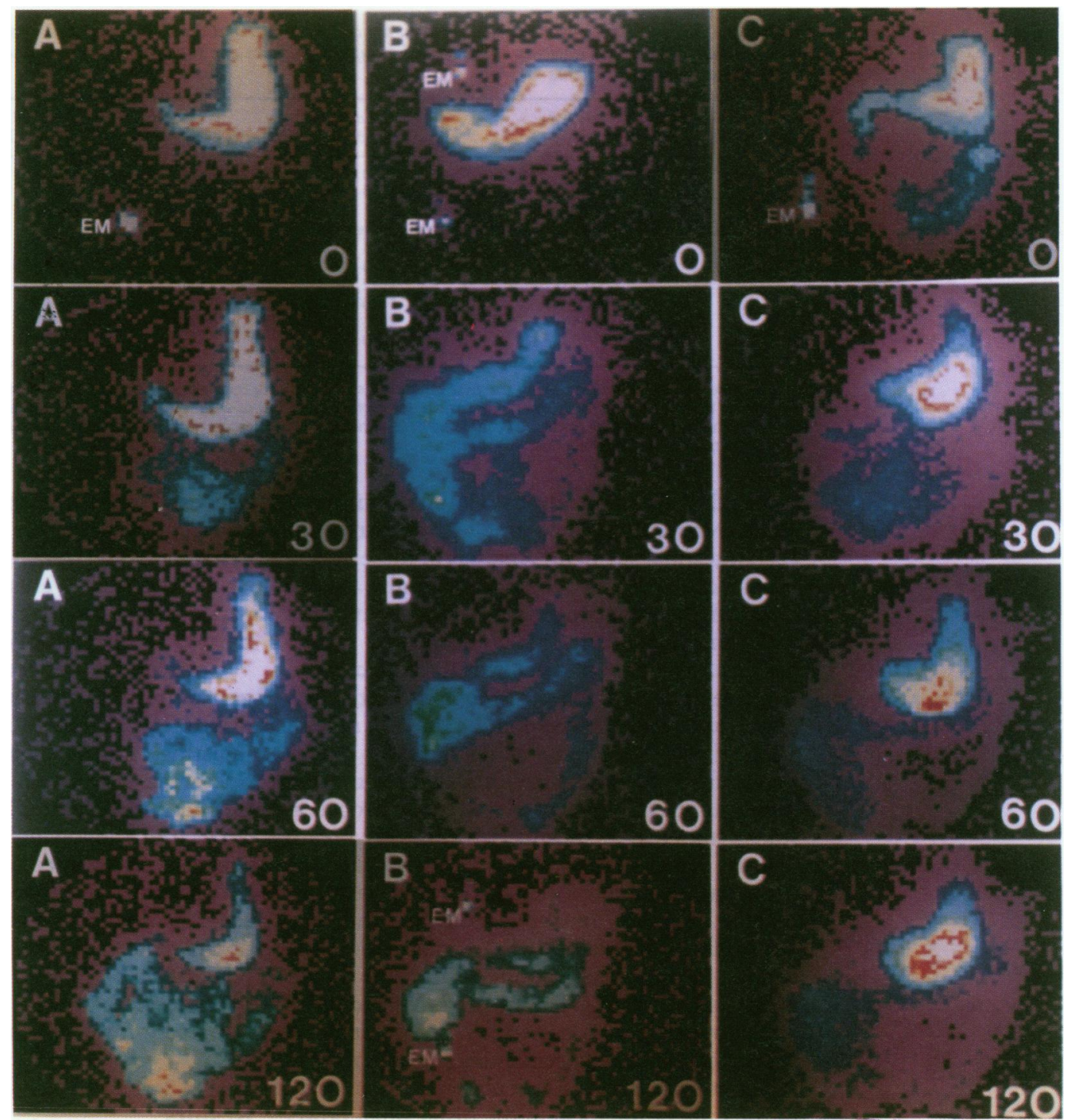

Figure 2: Serial gammacamera scans at different times (0,30, 60, and 120 minutes) after meal ingestion in three diabetics $(A, B$, and $C)$. In patient $A$, gastrointestinal transit was steady with accumulation of meal marker in the distal small bowe before caecal filling. In patient $B$ both gastric emptying and small bowel transit were very fast, with the tracer reaching the caecum at 30 minutes, without previous accumulation in the distal area. In patient $C$, the front of the meal emptied rapidly from the stomach and also reached the caecum rapidly. However, there was no subsequent gastric emptying nor any further progression of the marker through the small bowel. EM=external marker.

rapidly across the proximal small bowel and seemed to accumulate in distal segments, before the caecum was reached (Fig 2A). Seven diabetics (five from group DM-AN) showed a completely different pattern, with a trend towards more rapid gastric emptying and rapid transit through both proximal and distal small bowel segments. None of these patients showed evidence of accumulation of the tracer in the ileal region (Fig 2B). Lastly, another pattern was observed in one DM-AN patient with a biphasic pattern of gastric emptying. In this patient, the front of the meal emptied rapidly from the stomach and quickly reached the caecum. Therafter, no subsequent gastric emptying was noticeable nor was there any progression through the small bowel (Fig 2C).

Figure 3 shows the results concerning the time of meal arrival to the ROIs corresponding to the proximal and distal small bowel and to the caecum. There were no significant differences between the three groups regarding the time of meal arrival to the proximal and distal small bowel. However, the time of meal arrival to the caecum was significantly shorter in the DM-AN group (median; range $55 \mathrm{~min}$; $22->180 \mathrm{~min})$ than in the controls $(120 \mathrm{~min}$; $80->180 \mathrm{~min} ; \mathrm{p}<0.025)$ or the DM group ( 100 $\min ; 44->180 \min ; \mathrm{p}<0.05$ ).

Figure 4 shows the activity versus time curves constructed, for the ROIs corresponding to the stomach, the proximal and the distal small intestine, and the caecum. There were no significant differences between diabetics and controls regarding the values for activity in the ROI for the stomach (Fig 4A) and the proximal small bowel (Fig 4B) at any time point during the study. However, in the DM-AN group, activity in the ROI for the distal small bowel was consistently lower than in both the control and DM groups, with differences reaching statistical significance from 90 minutes up to the end of the study (Fig 4C). Activity in the ROI for the caecum in the DM-AN group was consistently higher than in both the controls and DM patients (Fig 4D). 

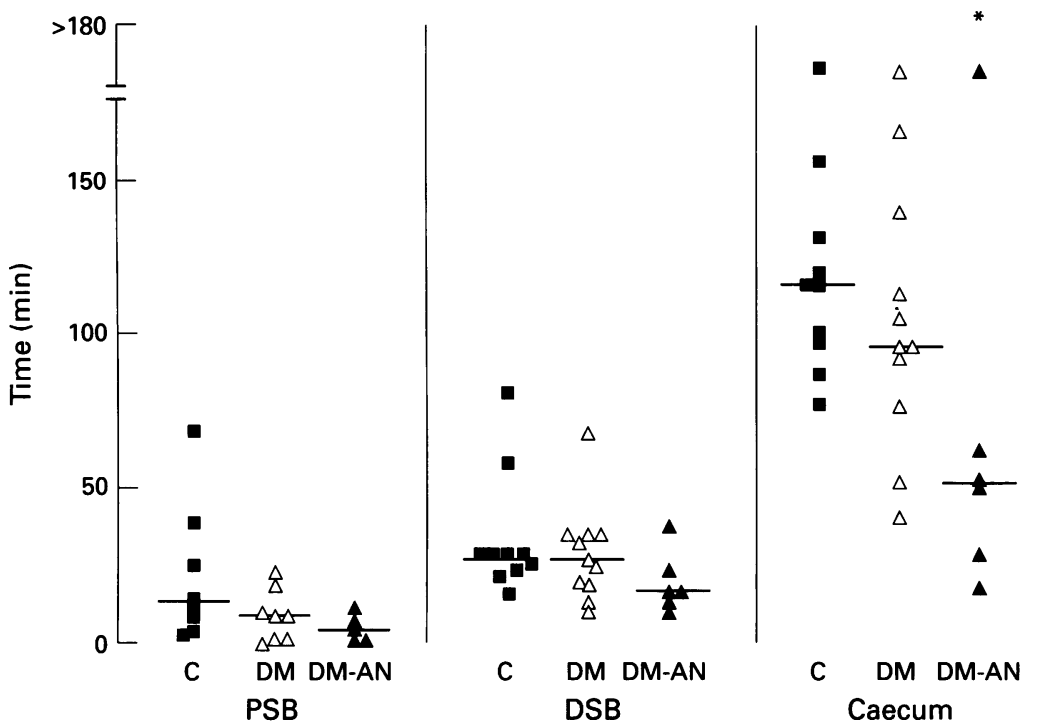

${ }^{*} \mathrm{p}<0.025 v$ controls; $\mathrm{p}<0.05 v \mathrm{DM}$

Figure 3: Time of meal arrival to proximal (PSB) and distal (DSB) small bowel segments, and to the caecum in controls (C) and in diabetic patients without (DM) and with evidence of autonomic neuropathy (DM-AN). Median values are given by the horizontal bars. In six cases ( $2 C, 3 D M$, and $1 D M-A N)$, activity in PSB throughout the study have not reached the minimum required for definition of the time of meal arrival.
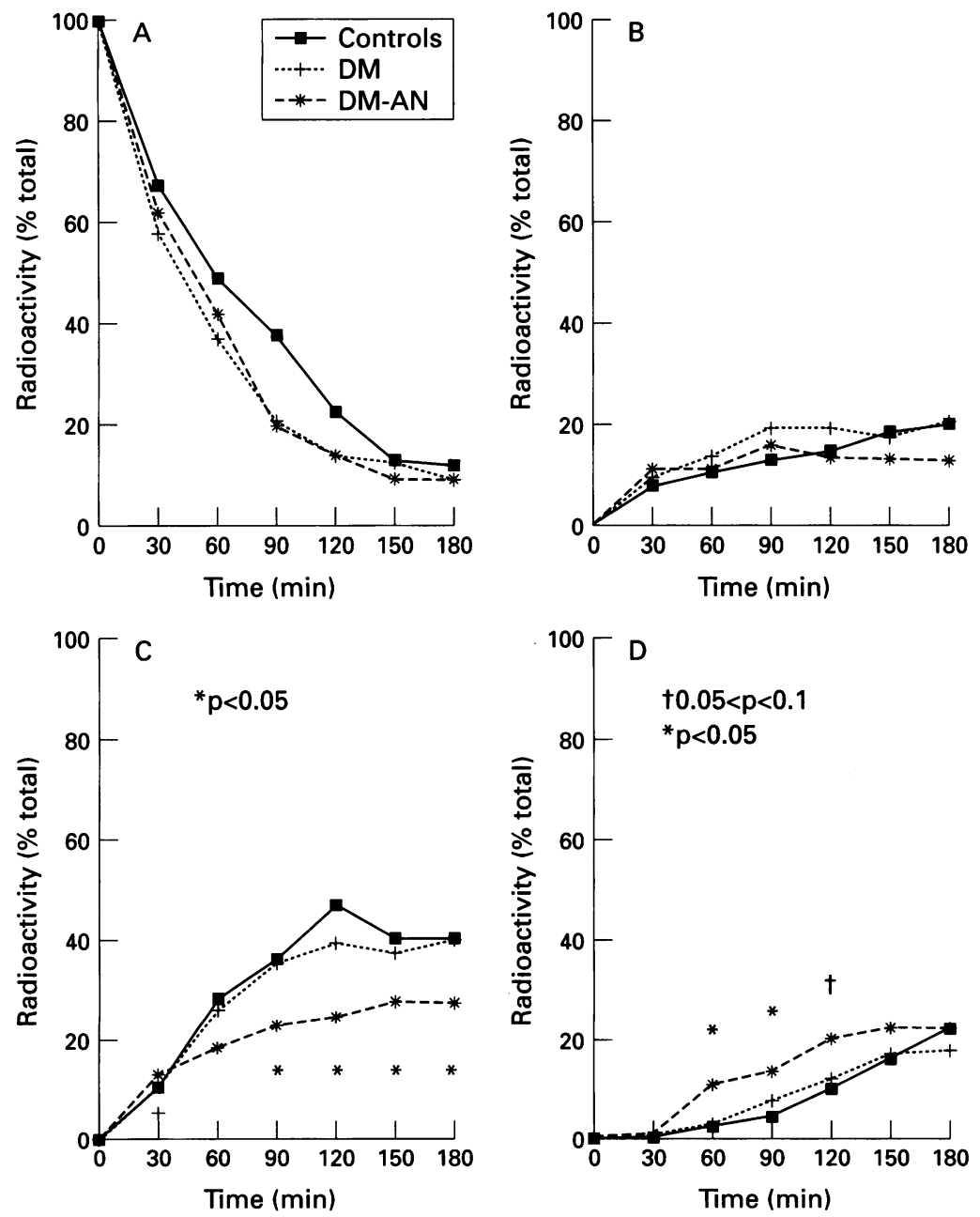

Figure 4: Activity time curves for the stomach $(A)$, the proximal $(B)$ and the distal $(C)$ small bowel, and the caecum (D) in controls and in diabetic patients without (DM) and with evidence of autonomic neuropathy (DM-AN). Data are presented as median values of activity at each time point, expressed as percentage of total abdominal activity.
Visual analysis of gammacamera scans and inspection of activity versus time curves suggested that, unlike controls and diabetics without autonomic neuropathy, diabetes mellitus patients with evidence of disautonomy lacked accumulation of chyme in the ileum with increased caecal filling (Fig 2 and Fig 4). This suggestion was supported by the fact that activity in the ROI for the distal small bowel by the time the tracer reached the caecum was significantly smaller for the DM-AN group (median; range: $23 \% ; 10-32 \%$ ) than for the controls $(38 \% ; 27-81 \% ; \mathrm{p}<0.01)$ and $\mathrm{DM}$ group (36\%; 15-78\%; p<0.05). Also, peak activity in the ROI for the distal small bowel in the DM-AN group (median; range: $30 \%$; $10-55 \%$ ) was significantly lower than in both the control $(50 \% ; 30-81 \%, \mathrm{p}=0.025)$ and $\mathrm{DM}$ groups $(49 \% ; 25-77 \%, \mathrm{p}=0 \cdot 025)$.

OCTT

The results concerning the arrival of the meal to the caecum were confirmed by the $\mathrm{H}_{2}$ breath test, although a clearly interpretable $\mathrm{H}_{2}$ profile was obtained in only seven controls and nine diabetic patients. Values for OCTT in the DM-AN group (median; range: $40 \mathrm{~min} ; 30-70$ min) were significantly shorter than in controls (150 min; 100-160 min; $p=0.008$ ) but were not significantly different from the DM group (90 $\mathrm{min} ; 50-170 \mathrm{~min}$ ). Also, there was no difference in OCTT values between DM and control groups.

CORRELATION BETWEEN OCTT AND $t_{c}$

There was a significant correlation $(r=0.79$; $\mathrm{p}<0.001)$ between $t_{C}$ obtained by scintigraphy and OCTT obtained by the $\mathrm{H}_{2}$ breath test.

CORRELATIONS BETWEEN GASTRIC EMPTYING AND GASTROINTESTINAL TRANSIT TIME

There was a significant correlation between early GE and the time of meal arrival to the proximal small bowel both in controls $(r=0.73$; $0.02<\mathrm{p}<0.05)$ and in diabetic patients $(r=0.76$; $\mathrm{p}=0.002$ ). However, no significant correlation was found between the remaining gastric emptying and intestinal transit data in any of the groups studied.

CORRELATIONS BETWEEN CARDIOVASCULAR AND GASTROINTESTINAL PARAMETERS

There were no significant correlations between any of the cardiovascular and the gastrointestinal parameters, except for that between postural hypotension and the time of meal arrival to caecum $\left(\chi^{2}=6.8 ; C=0.53 ; p<0.01\right)$, which was not surprising, because all DM-AN patients had postural hypotension.

CORRELATIONS BETWEEN DIARRHOEA, EVIDENCE OF AUTONOMIC NEUROPATHY, AND GASTROINTESTINAL TRANSIT

Diarrhoea was found to be significantly correlated with both the presence of cardiovascular 
evidence of autonomic neuropathy $\left(\chi^{2}=4.898\right.$; $\mathrm{C}=0.47 ; \mathrm{p}<0.05)$ and the values for the time of meal arrival to the caecum $\left(x^{2}=4.898\right.$; $\mathrm{C}=0.47 ; \mathrm{p}<0 \cdot 05)$.

\section{Discussion}

In this study, the application of a suitable scintigraphic technique to assess gastrointestinal transit allowed us to show that male type I diabetes mellitus patients with autonomic neuropathy have abnormally early arrival of the head of a liquid meal to the caecum and diminished accumulation of chyme in the distal small intestine.

A significant correlation between $t_{C}$ assessed by scintigraphy and OCTT measured by $\mathrm{H}_{2}$ breath test indicates that the isotope technique provides a valid way to estimate the arrival of the head of a test meal to the caecum, thus confirming previous observations. ${ }^{20}$ As far as the proximal and distal small bowel is concerned, no such validation is available, as there are no independent, physiological techniques to assess segmental small bowel transit. Nevertheless, the ROI for both the proximal and distal small bowel were defined according to the visual resolution of the progression of the isotope through successive segments and conformed with accepted topographic disposition for the jejunum and the ileum. ${ }^{22}$

Although there was a trend toward more rapid gastric emptying in both groups of diabetics compared with controls, no significant differences in gastric emptying rates were found between either group of diabetics and controls. This finding, as well as the lack of correlation between data for gastric emptying and intestinal transit measurements, indicate that the rapid gastric emptying of liquids that $\mathrm{we}^{4}$ and others ${ }^{23}$ have previously found in diabetes mellitus does not seem to be involved in the production of abnormally fast small bowel transit in patients with autonomic neuropathy.

Our findings of accelerated small bowel transit in diabetic patients with autonomic dysfunction are in agreement with the pioneering study by Malins and French, ${ }^{6}$ who used a radiological technique. Also, rapid small intestinal transit has been previously observed in some patients in a large group of diabetics. ${ }^{9}$ However, a number of other studies have demonstrated normal ${ }^{5910}$ or delayed $^{28}$ small intestinal transit in diabetics. A potential source for such discrepancies is diversity of criteria for patient selection. In an attempt to minimise variability caused by sex ${ }^{24}$ type of diabetes mellitus, ${ }^{25}$ and age, ${ }^{26}$ we have studied only male type I diabetics within a relatively narrow age range. Interestingly, the final composition of our group of diabetics had a few unexpected features. Firstly, we found a relatively high proportion of patients with diarrhoea in our previously unselected sample of male type I diabetes, even though diarrhoea was not a major clinical problem in these patients. This relatively high frequency of diarrhoea might be explained by either a particular pattern of referral of outpatients to our teaching hospital or by the fact that clinical evaluations were performed by physicians more prone to detect and record any minor digestive manifestation. Secondly, we found that all patients meeting the criteria for inclusion in the group with autonomic neuropathy (DM-AN) had objective evidence of orthostatic hypotension, which is known to indicate sympathetic dysfunction. ${ }^{13} 1516$ These findings enabled us to suggest a causative association between sympathetic denervation, rapid distal small bowel transit, and diarrhoea in diabetics.

The results of our transit study show that the proximal and distal regions of the small bowel have different roles in determining the abnormally fast arrival of the meal to the caecum. As previously shown by others, ${ }^{11}$ the jejunum and the ileum display different transit patterns after the ingestion of a liquid caloric meal. Chyme passes rapidly through the jejunum whereas the ileum seems to be a zone of accumulation. Accordingly, in all our controls and in nine of 11 diabetic patients without evidence of autonomic neuropathy, transit through the proximal and distal small bowel conformed to these patterns. In contrast, in the group of diabetics with autonomic neuropathy there was no evidence of accumulation in the distal small bowel, even though transit through the proximal intestine seemed to be preserved. This finding suggests that early arrival of the head of the meal to the caecum in diabetics with autonomic dysfunction is probably caused by motor disturbances affecting predominantly the ileum or the ileocolonic junction, or both. We cannot rule out, however, the possibility that accelerated distal small bowel transit is a consequence of impaired sodium and water absorption caused by sympathetic denervation of the ileum known to occur in diabetic neuropathy. ${ }^{27}$ The addition of lactulose to our test meal as a substrate for the $\mathrm{H}_{2}$ breath test might also have caused an accelerating effect on gastrointestinal transit due to its osmotic action. This passive effect, however, would be similar for normal subjects and diabetic patients and therefore could not be taken as the cause of the differences in transit herein shown.

The factors influencing transit through the more distal segments of the small bowel under normal conditions and the patterns of ileal transit in different diseases are still poorly understood. Greydanus $e t a l^{28}$ studied colonic filling after the ingestion of a solid meal and found that in healthy volunteers the ileocolonic transfer of chyme is characterised by bolus movements followed by plateaus, when no transfer was observed. Although our study assessed small bowel transit rather than colonic filling, it is plausible to assume that accumulation in the distal small bowel may correspond to the plateaus described by Greydanus et al. ${ }^{28}$

A few studies using scintigraphic techniques ${ }^{28}{ }^{29}$ have shown that small bowel transit and colonic filling after the ingestion of a solid meal are delayed among some diabetic patients who included a larger group of patients with intestinal pseudo-obstruction. The discrepancy 
between these results and ours might be due to differences in the pattern of gastrointestinal involvement in diabetes, because none of our patients had any evidence of obstructive features in their clinical picture. It is also noteworthy that, in contrast with others, ${ }^{28}{ }^{29}$ we assessed gastric emptying and small bowel transit only after the ingestion of a liquid meal with a relatively low fat concentration and containing lactulose. Our results therefore cannot be generalised to a solid, ordinary meal with higher lipid content. On the other hand, it is fairly well known that a solid test meal is more likely to disclose gastroparesis in diabetic patients than a liquid meal, which might account for delayed small bowel transit and colonic filling, as found by others. ${ }^{28} 29$

The lack of a close correlation between data for the cardiovascular and gatrointestinal measurements is not surprising and has been reported in other studies. ${ }^{10}$ This could be explained by regional differences in nerve dysfunction or low sensitivity of cardiovascular tests in detecting widespread denervation in diabetics. Nevertheless, there was a significant correlation only between orthostatic hypotension and early arrival of the meal marker to the caecum in the overall group of diabetics. As orthostatic hypotension in diabetics is thought to be caused by efferent sympathetic dysfunction, ${ }^{13} 15{ }^{16}$ it is possible that impairment of adrenergic influences on distal small bowel motor activity may be involved in the production of rapid distal small bowel transit in diabetics with autonomic neuropathy. This interpretation is consistent with previous findings suggestive of a prominent role of sympathetic influences in the control of human gastrointestinal transit. ${ }^{30}$ It has also been shown that sympathetic deprivation is probably involved in the production of upper gut dysmotility in diabetic patients with gastroparesis. ${ }^{31-33}$ and in water and chloride malabsorption in diabetic diarrhoea. ${ }^{34}$

Postprandial hyperglycaemia is an additional factor that could possibly contribute to small intestinal transit disorders in diabetic patients. Induced hyperglycaemia has been shown to inhibit gastric motility and emptying in healthy subjects ${ }^{3536}$ and to slow gastric emptying in diabetics. ${ }^{37}$ We attempted to reduce this putative influence of hyperglycaemia in our results by including only patients with satisfactory metabolic control. Also, fasting plasma glucose and urinary glucose excretion concentrations before the test in the group of diabetic patients with evidence of autonomic neuropathy were similar to those observed in the remaining patients. Although we cannot rule out an influence of hyperglycaemia on our results, it is unlikely that this factor contributed to transit acceleration, because at least in healthy volunteers small bowel transit is significantly prolonged during hyperglycaemia. ${ }^{38}$

The association between rapid small intestinal transit, autonomic dysfunction, and diarrhoea herein shown has already been recognised in a number of different conditions including diabetes ${ }^{6}{ }^{39}$ and postvagotomy diarrhoea. ${ }^{40}$ More recently, abnormally fast small intestinal transit of a liquid meal has been reported in eight patients with chronic diarrhoea and some form of autonomic dysfunction related to systemic disease, including diabetes mellitus. ${ }^{42}$

A number of mechanisms might be involved in the production of diarrhoea associated with autonomic dysfunction in diabetics. It is plausible that deranged small bowel motility caused by impaired neural influences on the gut may lead to exceedingly early transfer of chyme to the caecum, which would overload the large bowel and contribute to diarrhoea production, particularly when a hyperosmolar meal is ingested. Bile malabsorption ${ }^{43}$ might also be involved because decreased accumulation of chyme in the distal small bowel probably reduces the re-absorption of bile salts in the ileum. Impaired absorption of water and electrolytes associated with reduced $\alpha_{2}$ adrenergic activity, ${ }^{27}$ which has been proposed as a key factor in diarrhoea production in diabetic patients, ${ }^{34}$ might also result from diminished accumulation of chyme in the distal small bowel. Thus, rapid transit through the more distal segments of the small bowel could be a common component in the multifactorial origin of diarrhoea production in patients with diabetic autonomic neuropathy.

Rapid small intestinal transit and reduced accumulation of chyme in the distal small bowel of diabetic patients are unlikely to affect the absorption of nutrients and drugs that takes place mostly in the more proximal segments of the small bowel. It is plausible, however, that the transit abnormalities herein shown might interfere with the release of ileal neuropeptides, such as enteroglucagon, ${ }^{44}$ which are known to take part in glycaemic control. ${ }^{45}$

In conclusion, our findings indicate that type I diabetic patients with evidence of autonomic neuropathy have abnormally rapid progression of a liquid meal through the small bowel. The earlier arrival of chyme to the large bowel does not seem to be due to accelerated gastric emptying, but rather to a reduced accumulation in the more distal segments of the small intestine. These transit abnormalities in diabetic patients were found to be correlated with both the presence of orthostatic hypotension and the occurrence of diarrhoea. Although our findings cannot be fully generalised to an ordinary diet, it is suggested that impairment of sympathetic influences on distal small bowel motility might play a part in the acceleration of intestinal transit, which in turn might be involved in the production of diarrhoea in diabetes.

We are indebted to Mrs Christiane Souza e Silva and to $\mathrm{Mr} \mathrm{C}$ R Cambrea for excellent technical assistance. We also thank Professor J E Dutra de Oliveira and Dr N Iazigi, who allowed us to use equipment from their laboratories.

This study was supported by grants from CNPq-Conselho Nacional de Desenvolvimento Científico, FAPESP-Fundação de Amparo à Pesquisa do Estado de São Paulo, FAEPA-
Fundação de Amparo ao Ensino, Pesquisa e Assistência do Fundação de Amparo ao Ensino, Pesquín
Hospital das Clínicas de Ribeirão Preto.

1 Feldman M, Schiller LR. Disorders of gastrointestinal motility associated with diabetes mellitus. Ann Intern Med 1983; 98: 378-84.

2 Dooley CP, El Newhh HM, Zeidler A, Valenzuela JE. Abnormalities of the migrating motor complexes motor complex in diabetics with autonomic neuropathy and diarrhea. Scand $\mathcal{F}$ Gastroenterol 1988; 23: 217-23. 
3 Rundles RW. Diabetic neuropathy: general review with report of 125 cases. Medicine 1945; 24: 111-60.

4 Oliveira RB, Troncon LEA, Meneghelli UG, Dantas RO Godoy RA. Gastric accommodation to distension and early gastric emptying in diabetics with neuropathy. Braz f Med Res 1984; 17: 49-53.

5 Wegener M, Borsch G, Schaffstein J, Luerweg C, Leverkus F. Gastrointestinal transit disorders in patients with insulin-treated diabetes mellitus. Dig Dis 1990; 8: 23-6.

6 Malins JM, French JM. Diabetic diarrhoea. $Q \mathcal{F}$ Med 1957; 26: $467-80$.

7 Goldstein F, Wirts CW, Kowlessar OD. Diabetic diarrhea and steatorrhea: microbiologic and clinical observations. Ann Intern Med 1970; 72: 215-8.

8 Scarpello JHB, Greaves M, Sladen GE. Small intestinal transit in diabetics. BMF 1976; $2: 1225-6$.

9 Keshavarzian A, Iber FL. Intestinal transit in insulinrequiring diabetics. Am f Gastroenterol 1986; 81: 257-60.

10 Werth B, Meyer-Wyss B, Spinas GA, Drewe J, Beglinger C. Non-invasive assessment of gastrointestinal motility disorders in diabetic patients with and without cardiovascular signs of autonomic neuropathy. Gut 1992; 33: 1199-203.

11 Jian R, Pecking A, Najean Y, Bernier JJ. Étude de la progression d'un repas dans l'intesin grêle de l'homme par une méthode scintigraphique. Gastroenterol Clin Biol 1979; 3: 755-62.

12 Unger HR, Foster DW. Diabetes Mellitus. In: Textbook of endocrinology. Wilson JD, Foster DW, eds. WB Saunders Company, Philadelphia. 1985: 1018-80.

13 Marin Neto JA, Gallo Jr L, Manço JC, Rassi A, Amorim DS. Postural reflexes in chronic Chagas's heart disease. Cardiology 1975; 60: 343-57.

14 Santos e Fonseca CMC, Manço JC, Gallo Jr L, Barreira AA Foss MC. Cholinergic bronchomotor tone and airway caliber in insulin-dependent diabetes mellitus. Chest 1992; 101: 1038-43.

15 Marin Neto JA, Gallo Jr L, Manço JC, Rassi A, Amorim DS. Mechanisms of tachycardia on standing: studies in normal individuals and in chronic Chagas's heart patients. Cardiovasc Res 1980; 14: 541-50.

16 Ewing DJ, Clarke BF. Diagnosis and management of diabetic autonomic neuropathy. BMf 1982; 285: 916-8.

17 Read NW, Al-Janabi MN, Holgate AM, Barber DC Edwards CA. Simultaneous measurement of gastric emptying, small bowel residence and colonic filling of solid meal by the use of the gamma camera. Gut 1986 27: $300-8$.

18 Troncon LEA, Oliveira RB, Romanello LMF Rosa-e-Silva L, Pinto MCC, Iazigi N. Abnorma progression of a liquid meal through the stomach and small intestine in patients wtih Chagas' disease. Dig Dis Sci 1993; 38: 1511-7.

19 Tothill P, McLoughlin GP, Holt S, Heading RC. The effect of posture on errors in gastric emptying measurements. Phys Med Biol 1980; 25: 1071-7.

20 Caride VJ, Prokop EK, Troncale FJ, Buddoura W, Winchenbach K, McCallum RW. Scintigraphic determination of small intestinal transit time: comparison with mination of small intestinal transit time: comparison with the hydroge

21 Siegel S. In: Estatística não paramétrica-para as ciências do comportamento. Brasil: Editora McGaw-Hill, 1975.

22 Trier JS, Winter HS. Anatomy, embriology and develop mental abnormalities of the small intestine and colon. In: Sleisenger MH, Fordtran JS, eds. Gastrointestinal disease. Philadelphia: WB Saunders, 1989: 991-1021.

23 Phillips WT, Schwartz JG, McMahan CA. Rapid gastric emptying of an oral glucose solution in type 2 diabetic patients. F Nucl Med 1992; 33: 1496-500.

24 Wald A, Van Thiel DH, Hoechstetter L, Gavaler JS Egler KM, Verm R, et al. Gastrointestinal transit: the Egler KM, Verm R, et al. Gastrointestinal transit: the $1497-500$.
25 Dao T, Chée B, Bouvard G, Justum AM, Verwaerde JC Valla A. Lack of modulation of gastric emptying by acute hyperglycemia in type 2 diabetes mellitus. Gastroenterology 1990; 98: A342.

26 Moore JG, Tweedy C, Christian PE, Datz FL. Effect of age on gastric emptying of liquid-solid meals in man. Dig Dis Sci 1983; 28: 340-4.

27 Chang EB, Bergenstal RM, Field M. Diarrhea in streptozotocin-treated rats-loss of adrenergic regulation of intestinal fluid and electroyle transport. $\mathcal{F}$ Clin Invest 1985 75: $1666-70$.

28 Greydanus MP, Camilleri M, Colemont LJ, Phillips SF Brown ML, Thomforde GM. Ileocolonic transfer of solid chyme in small intestinal neuropathies and myopathies. Gastroenterology 1990; 99: 158-64.

29 Camilleri M, Brown ML, Malagelada JR. Impaired transit of chyme in chronic intestinal pseudoobstruction. Gastroenterology 1986; 91: 619-26.

30 McIntyre AS, Thompson DG, Day S, Burnham WR Walker ER. Modulation of human upper intestina nutrient transit by a beta adrenoreceptor mediated pathway. Gut 1992; 33: 1062-70.

31 Camilleri M, Malagelada JR. Abnormal intestinal motility in diabetics with the gastroparesis syndrome. Eur f Clin Invest 1984; 14: 420-7.

32 Camilleri M, Malagelada JR, Stanghellini V, Fealey RD, Sheps SG. Gastrointestinal motility disturbances in patients with orthostatic hypotension. Gastroenterology patients with orthos

33 Rosa-e-Silva L, Troncon LEA, Oliveira RB, Iazigi $\mathrm{N}$ Gallo Jr L, Foss MC. Treatment of diabetic gastroparesis with oral clonidine. Aliment Pharmacol Ther 1995; 9. 179-83.

34 Chang EB, Fedorak RN, Field M. Experimental diabetic diarrhea in rats - intestinal mucosal denervation hypersensitivity and treatment with clonidine. Gastroenteroloy 1986; 91: 564-9.

35 Barnett JL, Owyang C. Serum glucose concentration as a modulator of interdigestive gastric motility. Gastroenterology 1988; 94: 739-44.

36 MacGregor IL, Gueller R, Watts HD, Meyer JH. The effect of acute hyperglycemia on gatric emptying in man. of acute hyperglycemia on gatri

37 Fraser RJ, Horowitz M, Maddox AF, Harding PE Chatterton BE, Dent J. Hyperglycaemia slows gastric emptying in type 1 (insulin-dependent) diabetes mellitus. emptying in type 1 (insulin-dep

38 De Boer SY, Masclee AAM, Lam WF, Schipper J, Jansen JBMJ, Lamers CBHW. Hyperglycemia modulates gallbladder motility and small intestinal transit time in man. Dig Dis Sci 1993; 38: 2228-35.

39 Camilleri M, Vassalo M. Small intestinal motility and transit in disease. Baillieres Clin Gastroenterol 1991; 5: 431-51.

40 Ladas SD, Isaacs PET, Queresh Y, Sladen G. Role of the small intestine in postvagotomy diarrhea. Gastroenterology 1983; 85: 1088-93.

41 O'Brien JD, Thompson DG, McIntyre A. Effect of codeine and loperamide on upper intestinal transit and absorption in normal subjects and patients with post vagotomy in normal subjects and patients

42 Sellin JH, Hart R. Glucose malabsorption associated with rapid intestinal transit. Am $\mathcal{f}$ Gastroenterol 1992; 87: 584-9.

43 Ford GA, Preece JD, Davies IH, Wilkinson SP. Use of the SeHCAT test in the investigation of diarrhoea. Postgrad Med F 1992; 68: 272-6.

44 Spiller RC, Trotman IF, Adrian TE, Bloom SR, Misiewicz JJ, Gilin DBA. Further characterization of the 'ileal brake' reflex in man - effect of ileal infusion of partial digests of fat, protein and starch on jejunal motility and release of neurotensin, enteroglucagon and peptide YY. Gut 1988; 29: 1042-51.

45 Kreyman B, Williams MA, Ghatei A, Bloom SR. Glucagonlike peptide 17-36: a physiological incretin in man. Lancet 1987; ii: 1300-3. 